JUURNAL

of Health Inequalities

\title{
Global burden of pancreas cancer: regional disparities in incidence, mortality and survival
}

\author{
Cécile Pizot ${ }^{1}$, Miruna Dragomir ${ }^{1}$, Alina Macacu ${ }^{1}$, Alice Koechlin ${ }^{1,2}$, Maria Bota ${ }^{1,2}$, Peter Boyle ${ }^{1,2}$ \\ 'International Prevention Research Institute (iPRI), Lyon, France \\ ${ }^{2}$ Strathclyde University Global Public Health Institute, Lyon, France
}

\begin{abstract}
Introduction: Despite its low incidence, pancreas cancer is one of the most lethal cancers. This study aims to provide a global overview of pancreas cancer as to incidence, mortality and survival, in selected countries of the world.

Methods: Incidence was extracted from CI5plus and NORDCAN. Pancreas cancer deaths and populations were extracted from the WHO mortality database. Age-standardised incidence/mortality rates per 100,000 person-year were computed. Recent mean rates for incidence and mortality and annual percent changes (APC) over the last ten years were computed. Age-standardised relative survival was retrieved from the SEER database, Eurocare-5, NORDCAN and SURVCAN.

Results: Recently, incidence ranged from 2.0 in Uganda to 12.9 in Slovakia in men and from 1.3 in India to 7.3 in Slovakia in women. Mortality rates ranged from 1.3 in Thailand to 10.7 in Estonia in men and from 1.0 in Thailand to 6.7 in Finland in women. Over the last ten years, incidence increased in 21/26 countries in men (APC: $-6.09 \%$ in Uganda to $4.51 \%$ in India) and in 23 countries in women (APC: $-5.50 \%$ in Costa Rica to $6.51 \%$ in India). Increasing mortality trends were observed in $16 / 30$ countries for men (APC: $-2.62 \%$ in Northern Ireland to $4.73 \%$ in Thailand) and in 22 countries for women (APC: $-1.27 \%$ in Mexico to $4.80 \%$ in Thailand). Five-year survival ranged from $3.0 \%$ (Northern Ireland) to $17.2 \%$ (Hong Kong). Survival trends increased since the 1970 's from less than $5 \%$ to nearly $10 \%$ in recent years for USA and Northern Europe. Survival by stage indicated better survival for localised cancer with survival reaching $36 \%$ in 2010 compared to regional (11\%) and distant cancer (3\%).

Conclusions: Disparities in pancreas cancer incidence and mortality were observed worldwide. Globally, pancreas cancer survival remained low but increases in one-year relative survival and survival of localised cancer are promising.
\end{abstract}

KEY WORDS: pancreas cancer, incidence, mortality, survival, age-standardised rate, temporal trends.

ADDRESS FOR CORRESPONDENCE: Cécile Pizot, MSc, International Prevention Research Institute (iPRI), 95 Cours Lafayette, 69006 Lyon, France, phone: +33(0)4 721711 83, fax: +33(0)4 721711 90, e-mail: cecile.pizot@i-pri.org

\section{INTRODUCTION}

Cancer of the pancreas can affect either its exocrine or its endocrine functions, however, the large majority of tumours are exocrine pancreas cancers, with adenocarcinoma being the most common type and only $2-10 \%$ of pancreas cancers being pancreatic neuroendocrine tumours [1]. Pancreas cancer is mainly a disease of the elderly people that is often detected at an advanced stage due to the absence of symptoms associated with earlystage pancreas cancer and a lack of screening strategy.
Surgical resection offers the best chance to improve survival, but the majority of cases (80-85\%) are unresectable at diagnosis [2] mainly because of the advanced stage of the disease and the advanced age of patients.

Pancreas cancer is the fourteenth most common type of cancer in the world with approximately 458,918 new cases estimated in both men and women in 2018 [3]. Disparities in pancreas cancer incidence exist around the world, with developed countries more affected than developing countries. Due to its poor prognosis, with 
a five-year survival rate below $10 \%[4,5]$, pancreas cancer is the seventh leading cause of cancer death in both men and women worldwide, with approximately 432,242 deaths estimated in 2018 [3]. According to current trends, pancreas cancer mortality is projected to surpass that of breast and colorectal cancer by 2030 in the United States and Germany, and become the second leading cause of cancer death $[6,7]$. Pancreas cancer is an important public health issue worldwide that needs to be better understood. Understanding epidemiological trends might help identify and characterise risk factors and thus, provide further insight into pancreas cancer prevention.

The aim of this study is to provide updated temporal trends in pancreas cancer incidence, mortality and survival, and to present an overview of the current situation in selected countries of the world, mainly in countries with a national cancer registry.

\section{METHODS}

Pancreas cancer was defined according to the International Classification of Disease (ICD, $7^{\text {th }}$ to $10^{\text {th }}$ revisions) using the following codes: 157 in ICD-7 and ICD-8, B096 or 157 in ICD-9, C25 or 1032 in ICD-10. Only malignant neoplasms were considered in this study. The period of study was 1953 through 2015 which corresponded to the longest period of available data.

\section{COUNTRY SELECTION}

The following countries, with a national cancer registry for both incidence and mortality, were selected for analysis: Bulgaria, Costa Rica, Croatia, Denmark, Estonia, Finland, Iceland, Lithuania, Netherlands, New Zealand, Northern Ireland, Norway, Scotland, Slovakia, Slovenia and Sweden. Some additional countries with regional registries for incidence were also selected: Australia, Brazil, Canada, Colombia, Japan, Thailand, the Republic of Korea and the United States of America (USA). More details on the regional registries included can be found in Appendix S1. In order to give a global overview of the pancreas cancer situation in the world, India and Uganda were added to the incidence analysis and Chile, Hong Kong, Israel, Mexico, Singapore and South Africa were added to the mortality analysis. These additional countries for mortality were chosen according to the geographical location, the number of available years and the quality of data [8]. Trends in pancreas cancer incidence and mortality are presented by region as follows: Western Europe, Eastern Europe, Africa and Middle-East, Asia, Oceania, North America and, South and Central America.

\section{INCIDENCE DATA}

Yearly age-standardised incidence rates were extracted by gender from the Cancer Incidence in Five Continents database [9] for each country, except for the North- ern European countries, for which data was extracted from the NORDCAN database [10].

\section{MORTALITY DATA}

Pancreas cancer deaths registered in the World Health Organization (WHO) [11] mortality database in November 2018 were extracted by country, gender and five-year age group. Population data were also extracted from the WHO database and from the World Population Prospects of United Nations [12] when years were missing. When data were not available for one or two consecutive years, missing data were replaced by interpolations between previous and subsequent calendar years. Due to missing data between 1968 and 1997 in Costa Rica, Chile and Mexico, the period of study for mortality data began in 1997 for Costa Rica and Chile, and in 1998 for Mexico.

\section{SURVIVAL DATA}

Several data sources were used to retrieve data on pancreas cancer survival. The SEER database (Surveillance, Epidemiology, and End Results), which collects cancer related data from cancer registries across the USA, was explored with the SEER ${ }^{\star}$ Stat software. Age-standardised relative survival data were extracted, for the period 1973 to 2015 , by cancer stage, year of diagnosis, gender, and survival duration. Stages at diagnosis were classified as: localised, regional, or distant tumours. The Eurocare5 project studies cancer survival in Europe and makes freely available online cancer survival data by cancer site, country, gender, and survival duration, for the period 2000-2007 [13]. More detailed survival analyses were available for Nordic European countries through the NORDCAN project [10], specifically trends in pancreas cancer survival between 1966 and 2018. A limited number of data was available for countries outside Europe and the USA, through the SURVCAN project [14], which provided survival data for Korea, Singapore, India, Thailand, and Hong Kong. Data was available for several cancer registries for each country, and an average survival among registries was extracted. A literature search of the PubMed database was also performed, in order to identify age-standardised five-year relative survival data for countries included in this study (Appendix S2). One publication was identified, reporting five-year age-standardised relative survival for Canada [15].

\section{STATISTICAL ANALYSIS}

For both incidence and mortality, age-standardised rates were computed using the Segi world standard population and are reported per 100,000 person-years. In Iceland rates fluctuated greatly over the period because of its small population size, therefore, a five-year smoothing average was used to represent the data. In order to compare recent situations between different regions of the world, mean rates were computed for each country considering the period 2010-2012 for incidence and 
2013-2015 for mortality. Also, annual percent changes (APC) over the last ten available years (2003-2012 for incidence and 2006-2015 for mortality) were computed using a linear regression of the log-transformed rates. All analyses were performed for men and women separately.

For survival, only age-standardised relative survival values were extracted from each data source, for comparison purposes. Relative survival corresponds to the probability of surviving cancer in the absence of other cause of death and is defined as the ratio of the observed survival of patients to the survival expected in the general population (for the same gender, age group and calendar time). Since the underlying age structure of countries' populations is different, age-standardised relative survival is employed, generally using the International Cancer Survival Standards (ICSS) [16]. All data sources provided age-standardised relative survival, however Eurocare and SEER data used the ICSS, NORDCAN data used age-standardisation with age groups different from the ICSS, and SURVCAN data used an alternative approach to age-standardisation [14].

\section{RESULTS}

\section{INCIDENCE}

Temporal trends in pancreas cancer incidence are presented by region in Figure 1A and Figure 1B for men and women, respectively. Incidence rates were generally higher in men than in women with men to women ratios computed on the recent years (2010-2012) ranging from 1.1 in Uganda to 1.9 in Estonia and Lithuania. Also, in recent years (2010-2012), incidence rates of pancreas cancer varied greatly across countries with rates ranging from 2.0 in Uganda to 12.9 in Slovakia in men and from 1.3 in India to 7.3 in Slovakia in women (Figure 2).

\section{Western Europe}

In Western Europe, similar figures were observed for both genders with a steady increase until the 1980's followed by decreases or level-off. In the last ten years (2003-2012) decreases were observed in Finland, Iceland and Norway in men while increases were observed in Denmark, the Netherlands, Northern Ireland, Scotland and Sweden. In women, increases were observed in all countries except in Finland where there was a tendency towards a decline in incidence. However, these variations were statistically significant only for the Netherlands (both genders) and for men from Denmark and Scotland. Also, in recent years (2010-2012), highest incidence rates were observed in Denmark (9.5 in men and 7.2 in women) and Finland (9.6 in men and 7.6 in women) for both genders while the lowest incidence rates were observed in Sweden (6.0 in men and 5.1 in women).

\section{Eastern Europe}

In Eastern Europe, a tendency towards an increase in incidence was observed in most countries and for both gen- ders. These tendencies were confirmed in the last ten years with APC ranging from $1.06 \%$ to $5.00 \%$ in women and from $0.26 \%$ to $1.98 \%$ in men. Incidence rates appeared more similar in women than in men for whom a larger variability is observed over the period. In recent years (2010-2012), the highest incidence rates were observed in Slovakia for both men (mean of 12.9) and women (mean of 7.3) while the lowest rates were noticed in Slovenia for men (mean of 9.1) and in Bulgaria for women (mean of 5.3).

\section{Africa and the Middle-East}

In Africa and the Middle-East, data on pancreas cancer incidence remained generally scarce. Regional data were only available for Uganda on a short period of time (1993-2012). During this period, incidence rates fluctuated considerably and similar rates were observed for both genders with a men to women ratio of 1.1. A tendency towards an increase in incidence was observed since 1993, with incidence rates varying from 0 to 1.6 in men and from 0.7 to 2.0 in women. The analysis of the last ten years (2003-2012) indicated a tendency towards a decrease in incidence in men $(\mathrm{APC}=-6.09 \%)$ and an increase in women (APC $=4.36 \%$ ). However these trends were not statistically significant.

\section{Asia}

In Asia, temporal trends in incidence were similar for both genders. However, two groups of countries could be observed: one group with Japan and Republic of Korea (Eastern Asia) that showed incidence rates more than 3.5 times higher than the second group with India and Thailand (Southern Asia). In the last ten years (20032012), incidence rates increased for all countries. However, these increases were statistically significant only for Japan $(\mathrm{APC}=1.68 \%)$ and Thailand $(\mathrm{APC}=4.48 \%)$ in men and for Japan $(\mathrm{APC}=2.48 \%)$ and the Republic of Korea $(\mathrm{APC}=1.71 \%)$ in women.

\section{Oceania}

In Oceania, slightly higher incidence rates were observed in Australia compared to New Zealand in men over the common period of available data (1993-2012), while in women similar rates were observed. In Australia, incidence rates increased from 6.6 to 7.7 in men and from 4.9 to 5.9 in women, while in New Zealand, incidence rates remained stable for men and they increased from 4.8 to 6.3 in women. In recent years (2003-2012), incidence rates significantly increased for both countries for women, with APC of $1.52 \%$ for Australia and $2.57 \%$ for New Zealand. In men, this significant increase was observed only in Australia (APC of 1.36\%), while it was not statistically significant for New Zealand.

\section{North America}

In North America, higher incidence rates were observed in the USA compared to Canada, for both gen- 
A

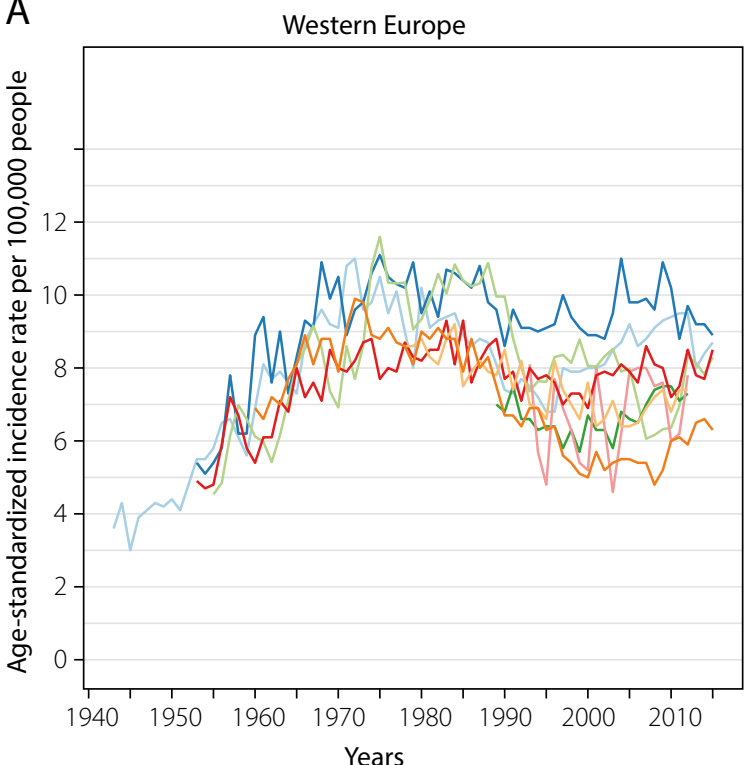

- Denmark APC $=1.21 \%$ - Finland APC $=-0.54 \%$ - Iceland APC $=-2.9 \% \quad-$ Netherlands APC $=2.14 \% *$ - Northern Ireland APC $=1.93 \% \quad$ - Norway APC $=-0.08 \%$ - Scotland APC $=1.3 \%^{*} \quad$ - Sweden APC $=1.05 \%$

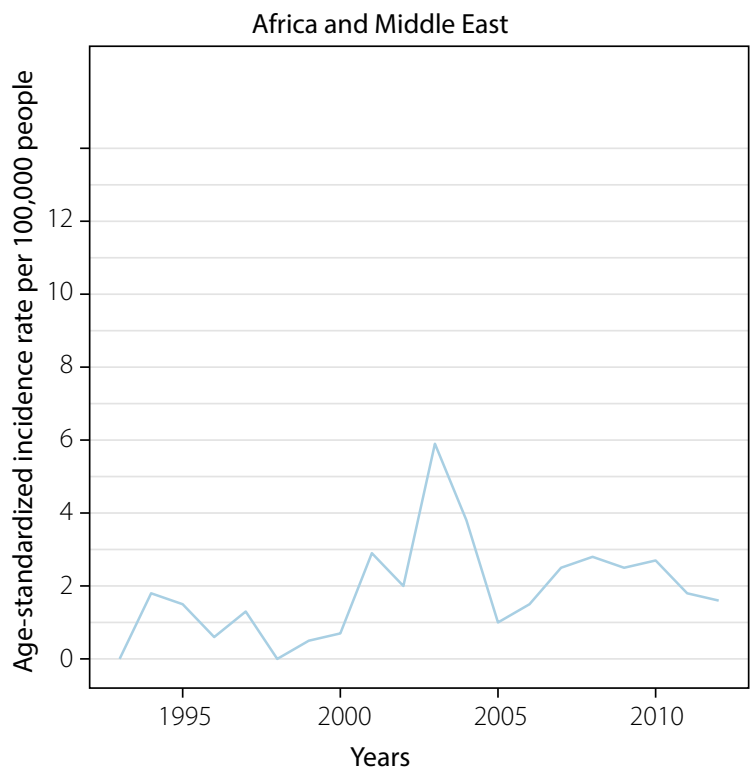

- Uganda (Kampala) APC $=-6.09 \%$
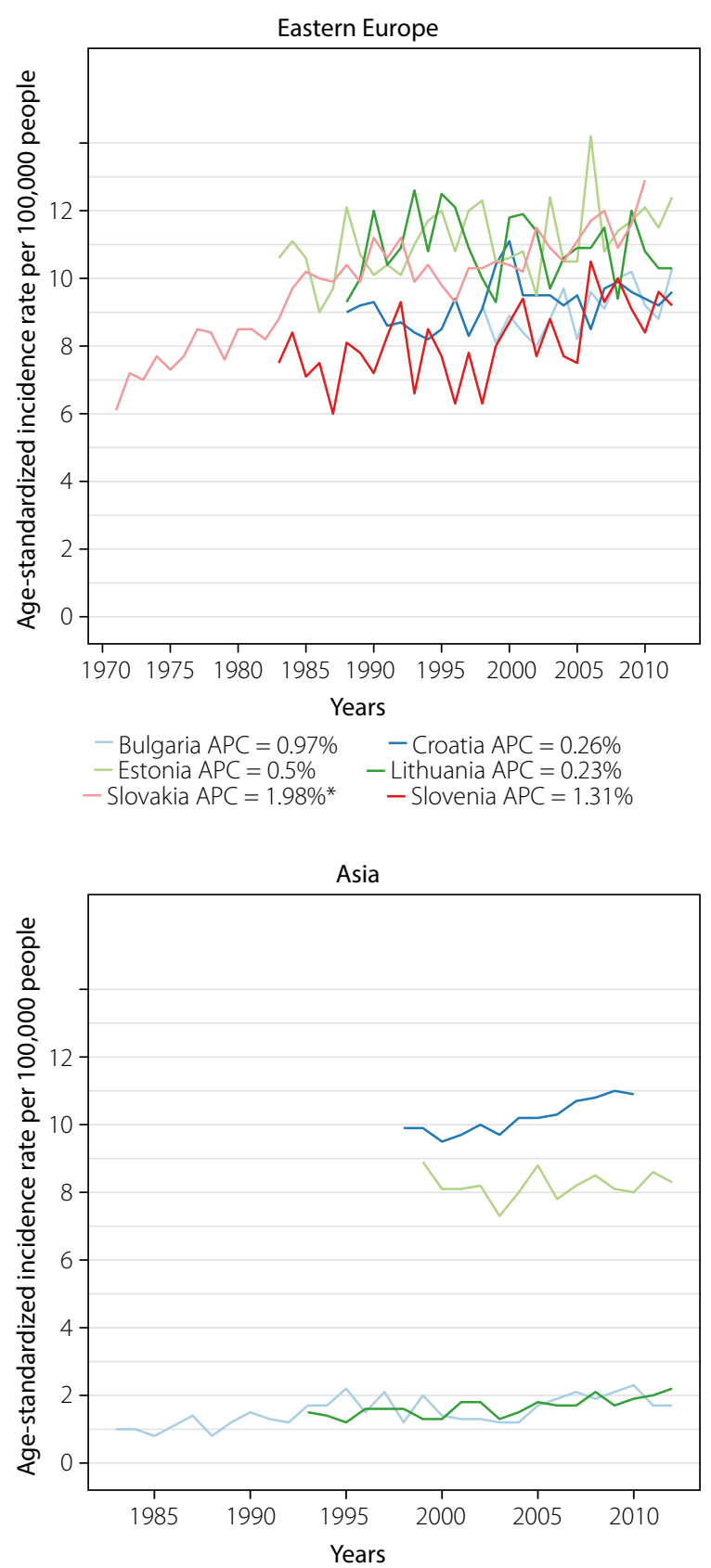

- India (Chennai) APC $=4.51 \%$ - Japan (4 registries) APC $=1.68 \%$ - Republic of Korea (5 registries) APC $=0.81 \%$

- Thailand (4 registries) APC $=4.48 \%$ *

FIG. 1. Temporal trends in pancreas cancer incidence in men $(\mathbf{A})$ and women (B), by region. APC - annual percentage change computed for the last 10 years 2003-2012

ders, over the period 1983-2012. In women, the trends appeared relatively stable until the end of the 1990's, while in men the trends showed a slightly decrease. In recent years (2003-2012), incidence rates significantly increased for both countries for women with APC of $0.87 \%$ for Canada and $1.04 \%$ for the USA. In men, this increase was observed only in the USA (APC $=0.79 \%$ ) while a stabilisation was observed in Canada $(\mathrm{APC}=0.27 \%$, not significant).

\section{Central and South America}

In Central and South America, temporal trends in incidence were similar for both genders and fluctuated notably over the available period of data. In the last ten years (2003-2012), incidence rates significantly decreased for men in Costa Rica (APC $=-5.14 \%$ ) (Figure 3). A tendency towards decreasing rates was observed in women from Costa Rica and Brazil, while a tendency towards increased rates was observed in both genders for Colombia, and only 


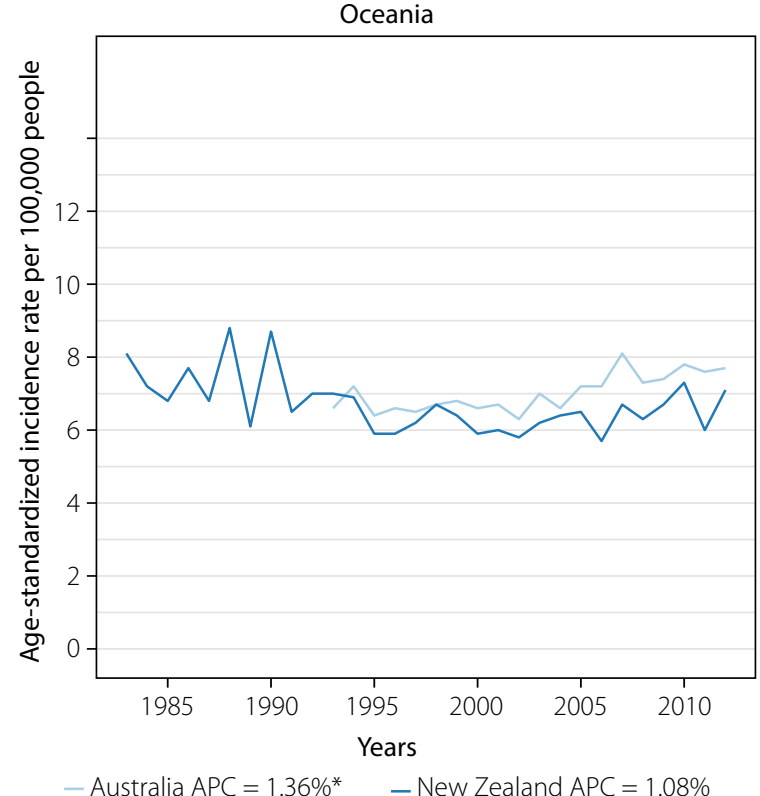

- Australia APC $=1.36 \%^{*} \quad$ - New Zealand APC $=1.08 \%$

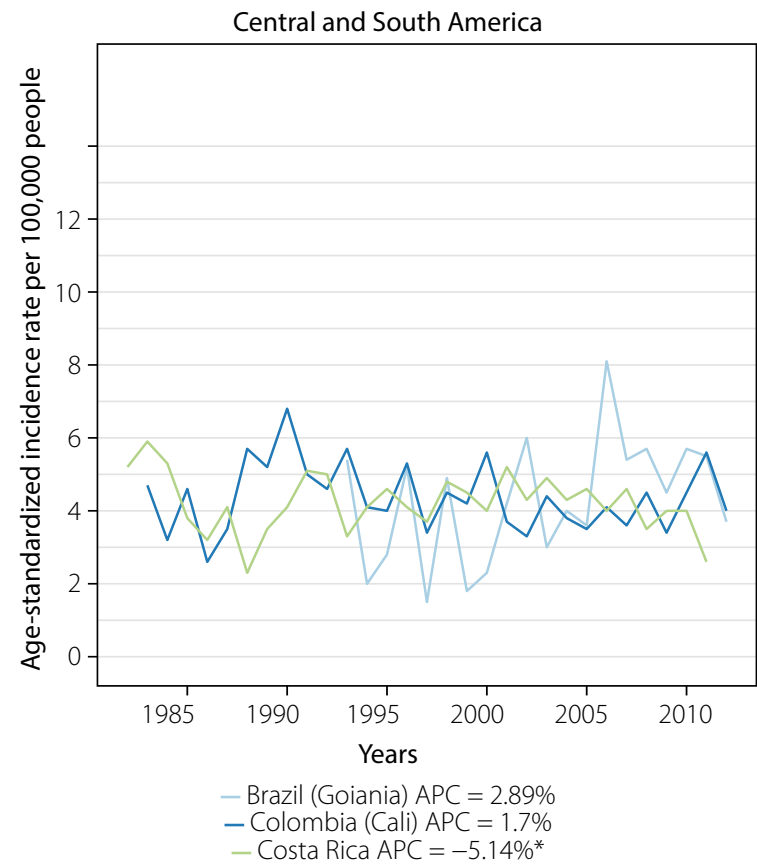

in men for Brazil. However, due to high variability in incidence rates, the APC were not statistically significant.

\section{MORTALITY}

Temporal trends in pancreas cancer mortality are presented by region in Figure 2A and Figure 2B for men and women, respectively. Mortality rates were generally higher in men than in women with men to women ratios computed on the recent years (2013-2015) ranging from 0.9 in Costa Rica to 1.9 in Bulgaria and Lithuania. Also, in recent years (2013-2015), mortality rates of pancreas cancer varied greatly across countries with rates ranging from 1.3 in Thailand to 10.7 in Estonia in men and from 1.0 in Thailand to 6.7 in Finland in women (Figure 4).

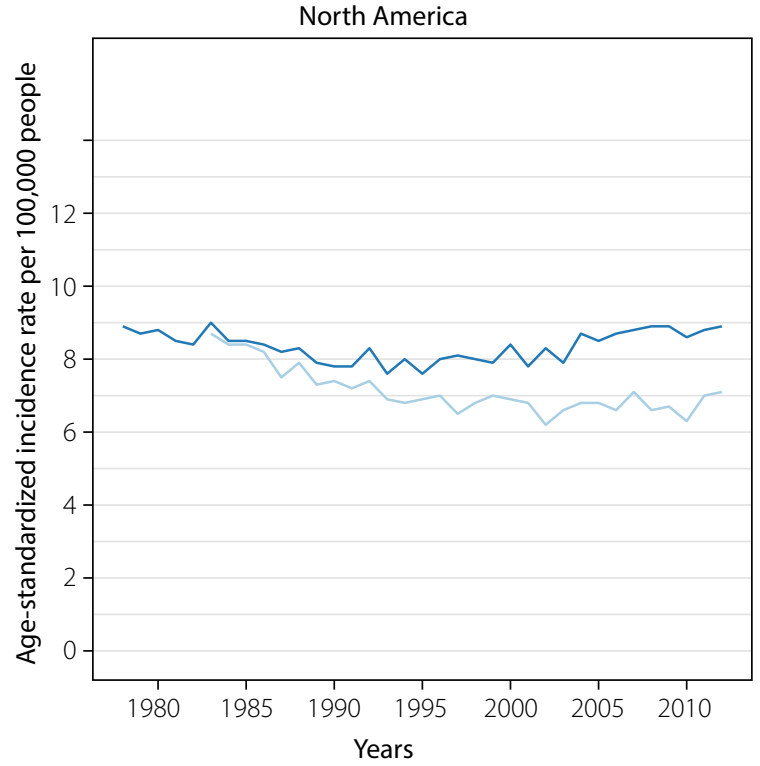

- Canada (regional) APC $=0.27 \% \quad$ - USA (SEER) APC $=0.79 \% *$

FIG. 1. Cont. (A) and women. APC - annual percentage change computed for the last 10 years 2003-2012

\section{Western Europe}

In Western Europe, similar pancreas cancer mortality trends were observed across countries.

In the fifties (1955-1959), the lowest mortality rates in men were observed in the Netherlands with a mean mortality of 4.8 , while the highest mortality rate was observed in Scotland with a mean mortality of 7.1. Recently (2013-2015), the lowest mortality rates were observed in Northern Ireland with a mean mortality of 6.5 , while the highest mortality rates were observed in Finland with a mean mortality of 8.7 (Figure 4). Increases in mortality rates were observed in all countries until 1970-1980, then declining trends occurred until 2000 followed by a stabilisation of the rates until 
B
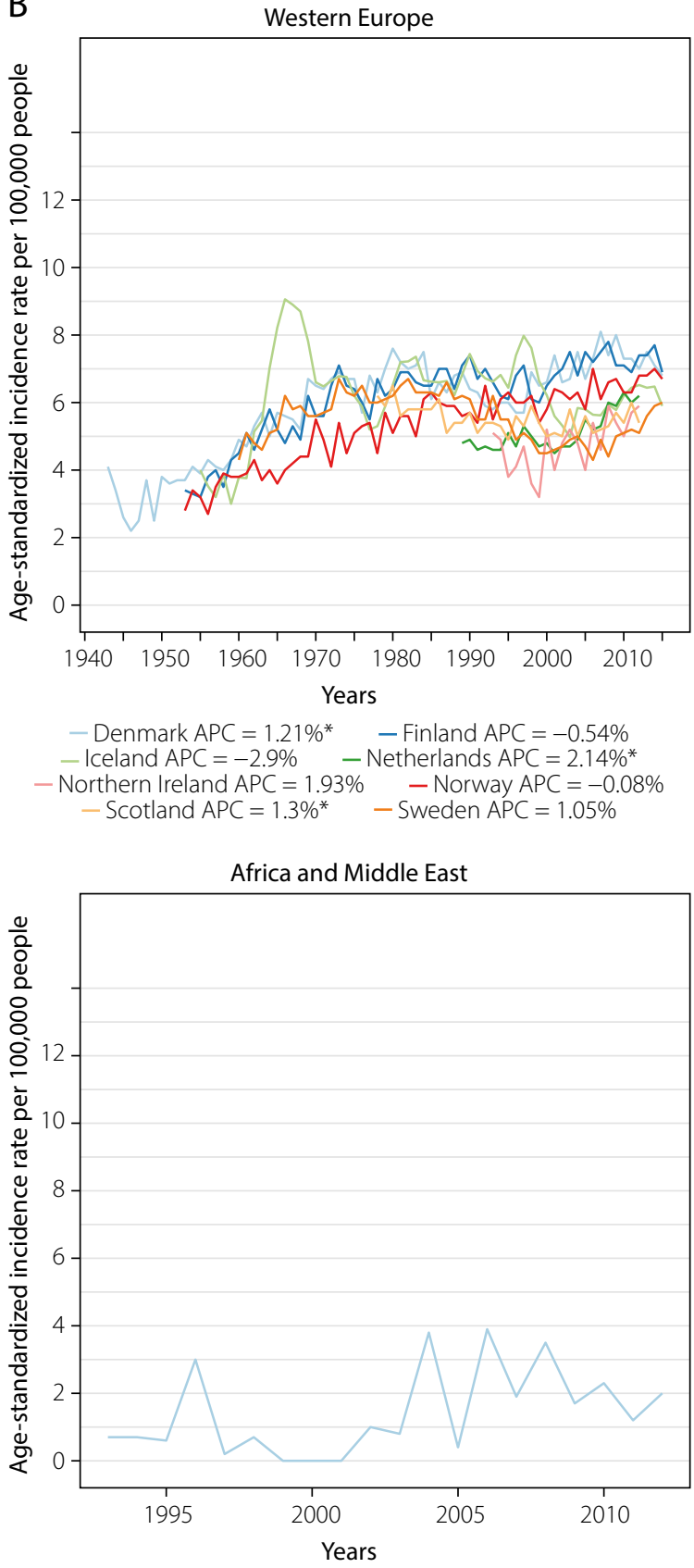

- Uganda (Kampala) APC $=-6.09 \%$
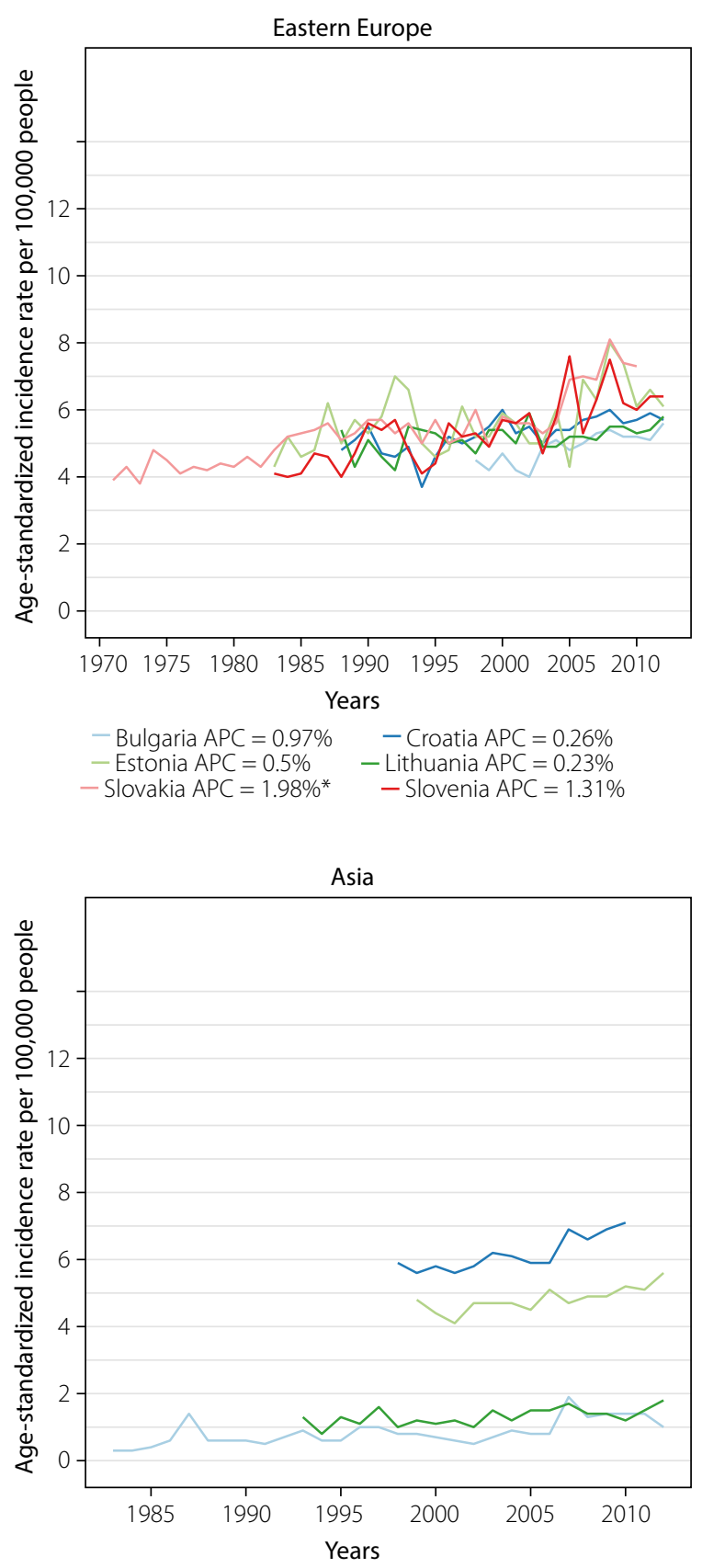

- India (Chennai) APC $=4.51 \%$ - Japan (4 registries) APC $=1.68 \% *$

Republic of Korea (5 registries) APC $=0.81 \%$

- Thailand (4 registries) APC $=4.48 \% *$

FIG. 1. Cont. (B), by region. APC - annual percentage change computed for the last 10 years 2003-2012

2015. Globally, over the period 1955-2015, the highest increase in pancreas cancer mortality was observed in Finland (+91\%, from 4.6 to 8.8$)$ and the lowest increase was observed in Scotland ( $+2 \%$, from 6.4 to 6.5 ).

Similarly to men, pancreas cancer mortality trends in women increased from the fifties to the eighties and then the trends slightly declined or levelled off until 2015. In the fifties (1955-1959), the lowest mortality rates were observed in Norway with a mean mortality of 3.2, while the highest mortality rates were observed in Scotland with a mean mortality of 4.8 . In recent years (2013-2015), the lowest mortality rates were observed in Scotland with a mean mortality of 4.9 , while the highest mortality rates were observed in Finland 6.7. As in men, the highest increase in mortality over the period 1955-2015 was observed in Finland $(+100 \%$, from 3.4 to 6.8 ) and the lowest increase was observed in Scotland (+4\%, from 4.7 to 4.9$)$. 


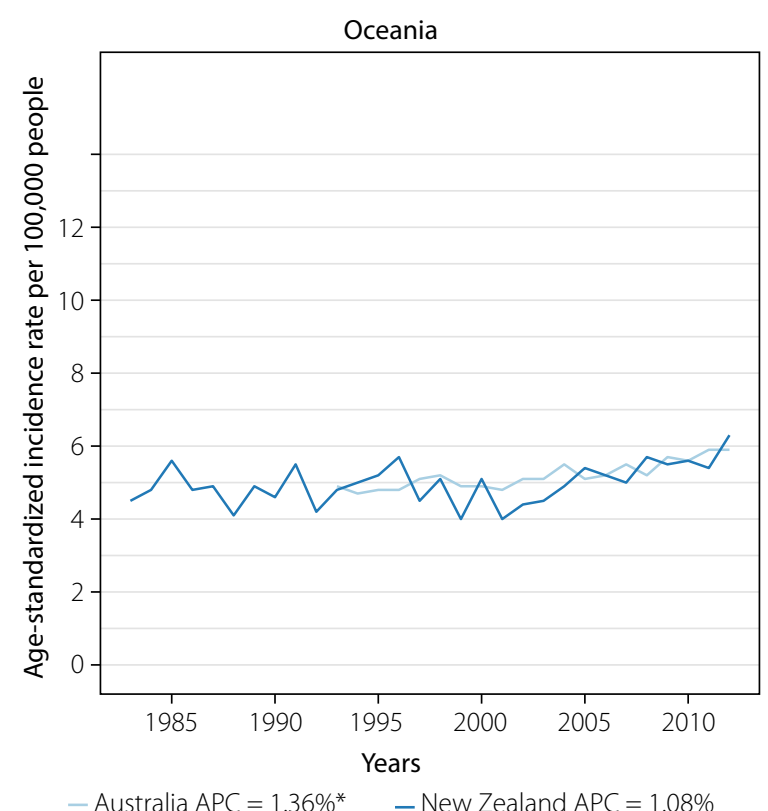

- Australia APC $=1.36 \%$ - New Zealand APC $=1.08 \%$

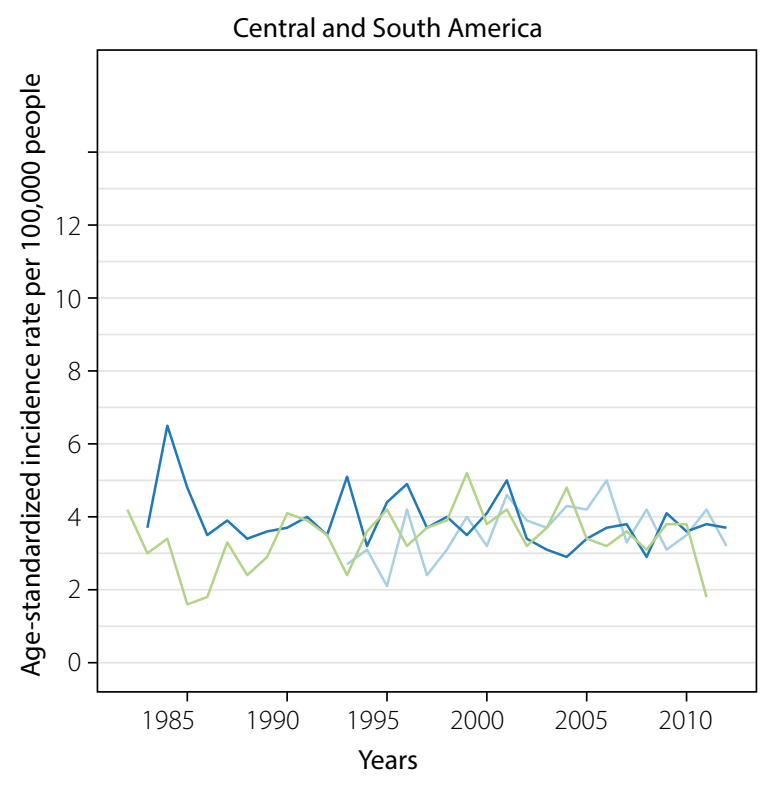

- Brazil (Goiania) APC $=2.89 \%$

- Colombia (Cali) APC $=1.7 \%$

- Costa Rica APC $=-5.14 \% *$

\section{Eastern Europe}

In Eastern Europe, data on pancreas cancer deaths were available later than in Western European countries.

In men, over the period 1985-2015, increasing mortality trends were observed in Bulgaria, Slovenia, Croatia and Slovakia, while more stable trends were observed in Estonia and Lithuania. In 1995-1999, when all the countries had data on pancreas cancer deaths, the highest mortality rates in men were observed in Estonia with a mean mortality of 10.7 and the lowest mortality rates were observed in Bulgaria with a mean mortality of 6.9. In recent years (2013-2015) the highest mean mortality was still observed in Estonia (mean of 10.7)

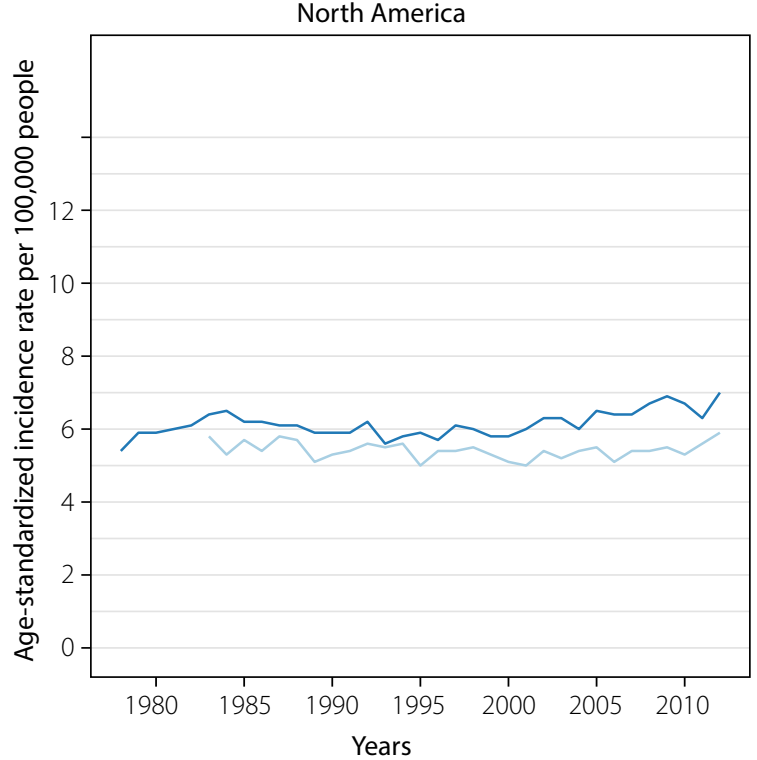

- Canada (regional) APC $=0.27 \%$ - USA (SEER) APC $=0.79 \%$ *

FIG. 1. Cont. (B), by region. APC - annual percentage change computed for the last 10 years 2003-2012

while the lowest mortality was observed in Croatia (mean of 8.4).

In women, pancreas cancer mortality increased for all countries over the period 1985-2015. In 1995-1999, mortality rates ranged from 3.5 in Bulgaria to 5.3 in Slovenia. In recent years, mean pancreas cancer mortality rates ranged from 4.7 in Bulgaria to 5.9 in Slovakia.

\section{Africa and the Middle-East}

Coverage of death registration was very low in Africa and the Middle-East, therefore only two countries were selected, one in each region. Mortality rates were about two-times higher in Israel than in South Africa over the period for both genders. 


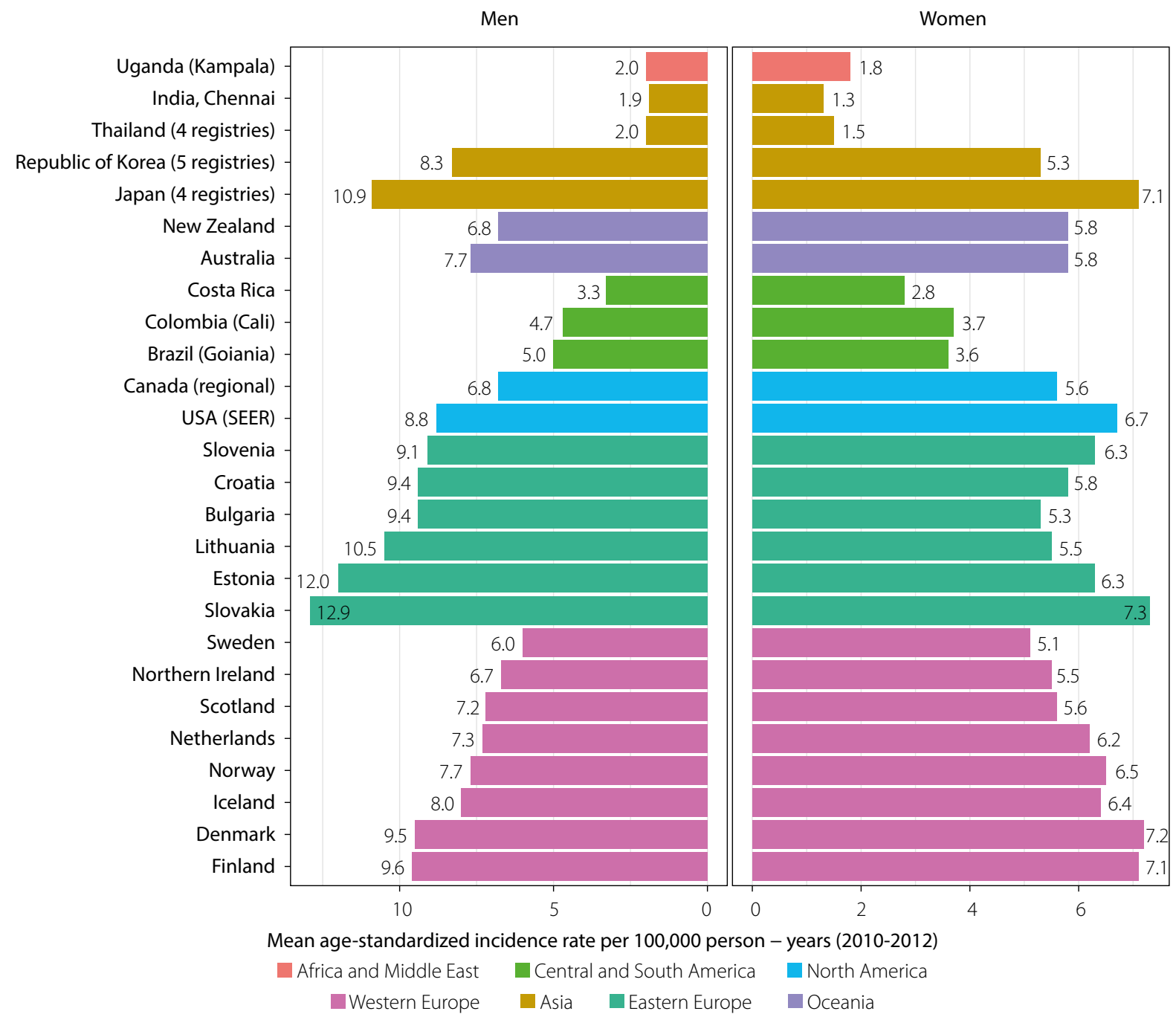

FIG. 2. Mean age-standardised pancreas cancer incidence over the period 2010-2012, by country and by gender

In Israel, a small decline in mortality was observed from 1975 to the 1990's followed by a slight increase until 2015. In South Africa, a stable trend was observed in men, while in women a slight increase in mortality was observed from 1993 to 2003 , followed by a decreasing trend until 2015 .

\section{Asia}

In Asian countries, similar figures of pancreas cancer mortality were observed for both genders with important increases observed in all countries, except in Hong Kong were the rates appeared more stable. In Japan, the rates increased from 1.8 in 1955 to 9.2 in 2015 in men and from 1.2 to 5.6 in women. The highest pancreas cancer mortality rates were observed in Japan with recent mean mortalities of 9.1 in men and 5.7 in women while the lowest rates were observed in Thailand with recent mortalities of 1.3 in men and 1.0 in women (Figure 4). The analysis of the last ten years (2006-2015) confirmed the increase in mortality in all countries for women, with APC ranging from $0.89 \%$ in
Singapore to $4.80 \%$ in Thailand. For men, this increase was also observed (APC range 0.48-4.73\%) except in the Republic of Korea where a small decrease was observed $(\mathrm{APC}=-0.09 \%)$.

\section{Oceania}

In Oceania, pancreas cancer mortality rates were comparable in Australia and New Zealand over the period 1955-2015. In women, slight increases in mortality were observed, with mortality rates varying from 3.6 in 1955-1959 to 4.6 in recent years (2013-2015) in Australia, and from 4.0 to 5.1 in New Zealand. In men, steady increases in mortality were observed until 1973 in Australia, and 1975 in New Zealand, when the highest mortality rates were observed (8.2 in Australia and 9.3 in New Zealand). Subsequently, declines in mortality occurred until the end of the 1990's, followed by a stagnation until recent years, when the rates became similar to the rates of the 1950's. The analysis of the last ten years indicated small increases for both countries for women 

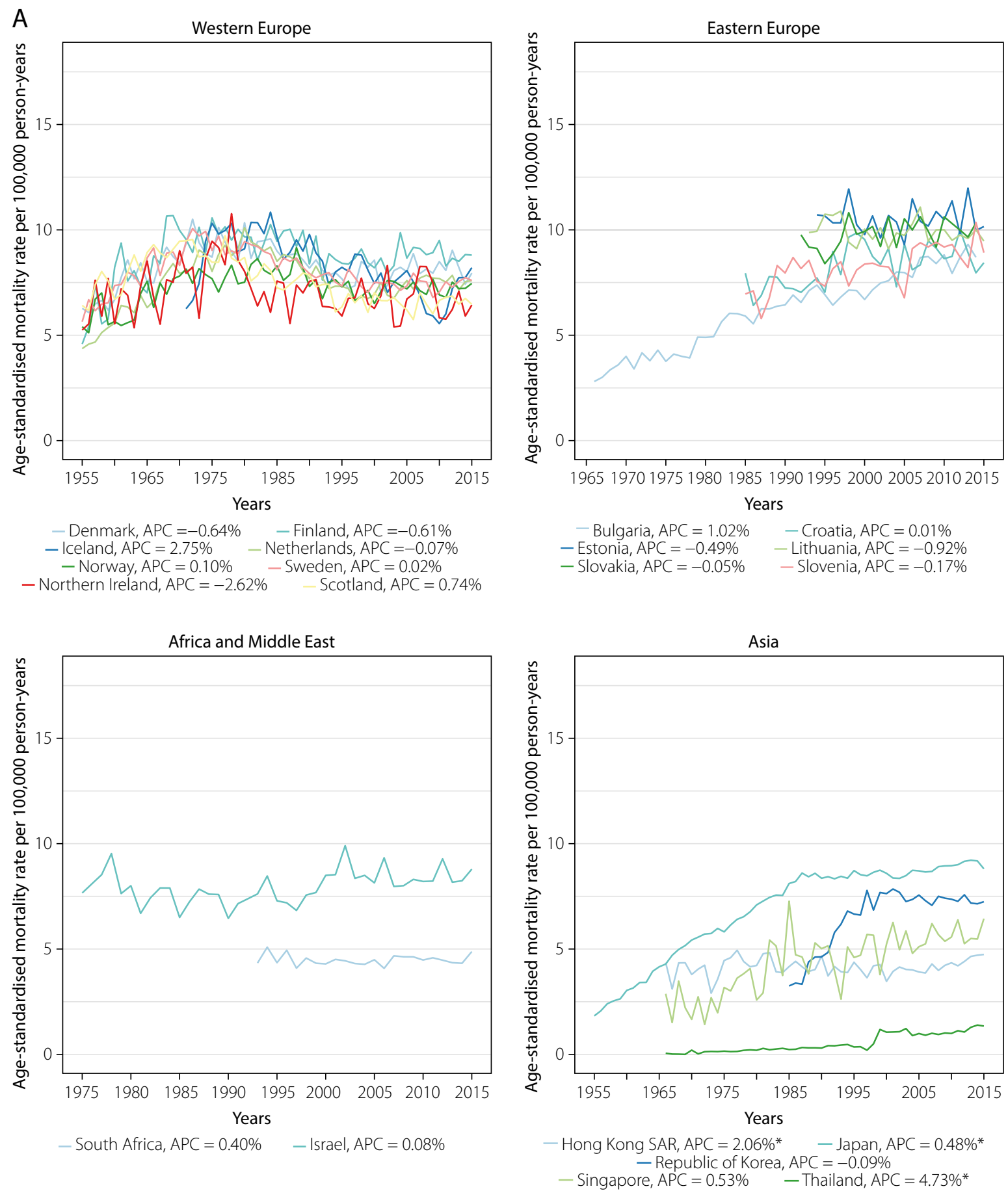

FIG. 3. Temporal trends in pancreas cancer mortality in men (A) and women (B), by region. APC - annual percentage change computed for the last ten years 2006-2015

(APC of $0.19 \%$ in Australia and $0.98 \%$ in New Zealand), while for men a small decrease was observed in Australia (APC of $-0.66 \%$ ) and a small increase in New Zealand $(\mathrm{APC}=0.85 \%)$.

\section{North America}

In North America, pancreas cancer mortality rates were comparable in Canada and USA over the period 1955-2015. In 1955-1959, similar mortality rates were

observed in both countries for both genders while in recent years (2013-2015), higher mortality rates were observed in the USA compared to Canada (7.4 vs. 6.9 in men and 5.4 vs. 5.2 in women). In men, steady increases in mortality were observed since 1955 until the early 1970 's then declines in mortality occurred until recent years when mortality became lower than in the 1950's. In women, slight increases in mortality were observed with mortality rates varying from 4.7 in 1955-1959 to 

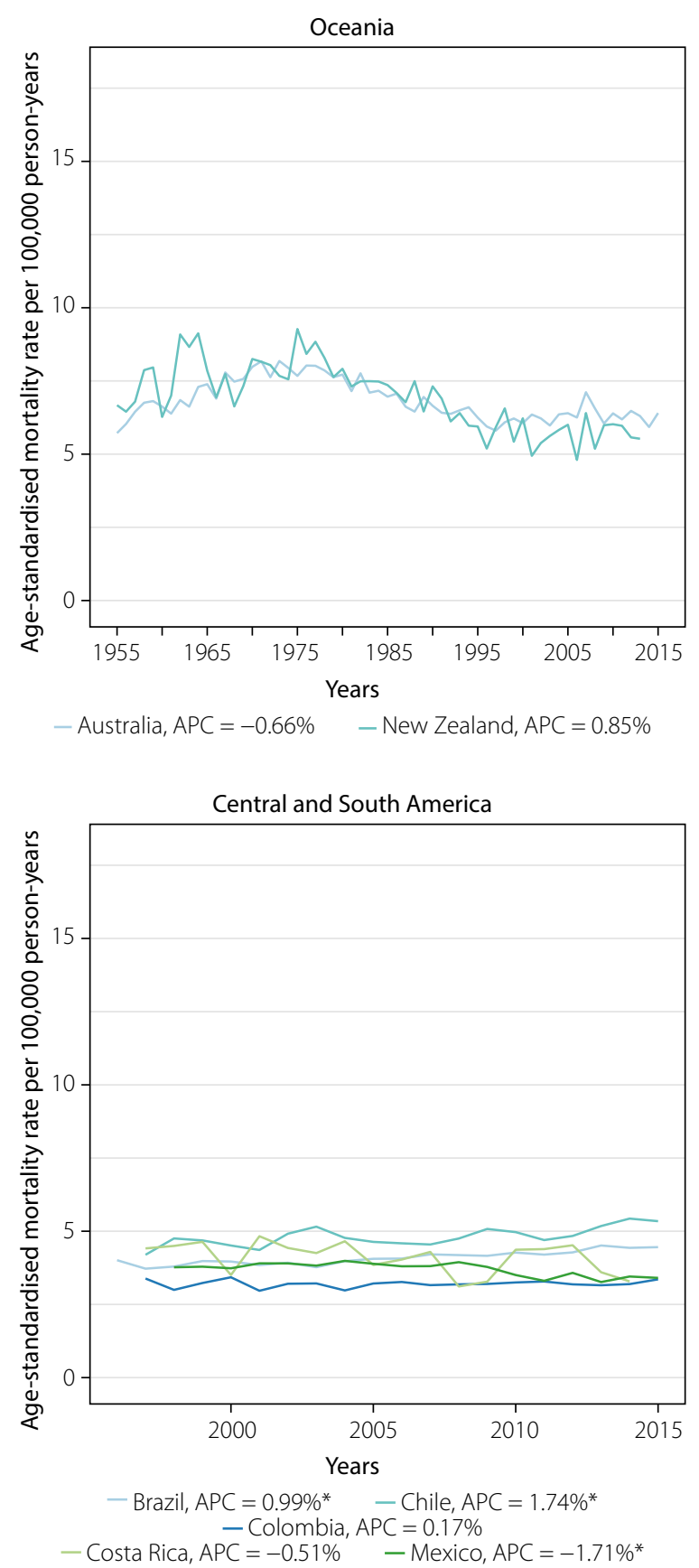

5.2 in recent years (2013-2015) in Canada, and from 4.6 to 5.4 in the USA.

\section{Central and South America}

In Central and South America, similar pancreas cancer mortality trends were observed in both genders over the period 1996-2015. Stable mortality trends were observed in Colombia, while small increases in mortality were observed in Chile and Brazil, and slight declines were observed in Mexico and Costa Rica. In recent years (2013-2015), the highest mortality rates were observed in Chile (5.3 in men and 4.4 in women), while the lowest rates were observed in Colombia (3.2 in men and 3.1 in women) (Figure 4).

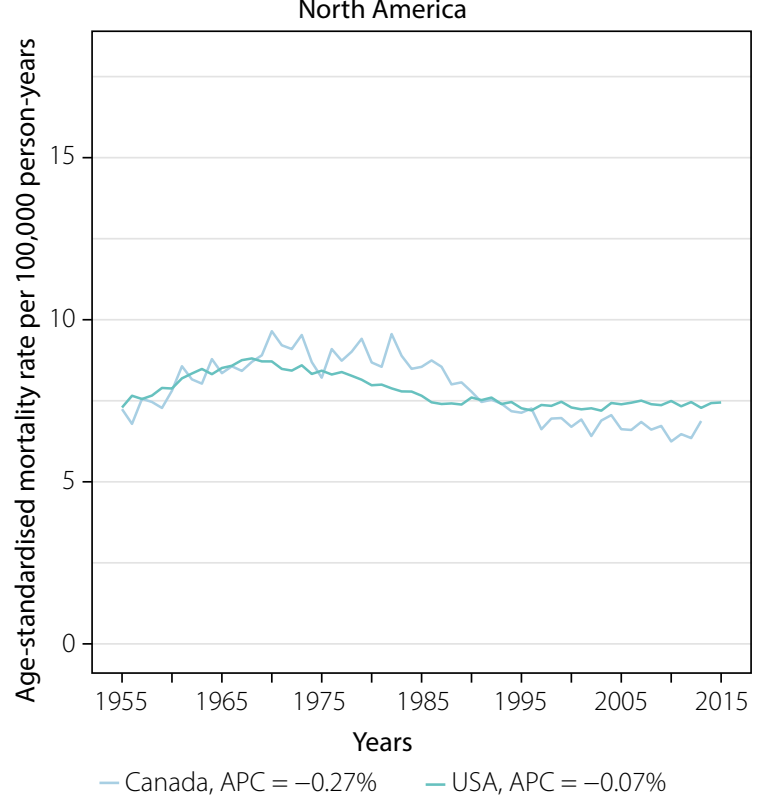

FIG. 3. Cont. (A) and women. APC - annual percentage change computed for the last ten years 2006-2015

\section{SURVIVAL}

Age-standardised five-year relative survival for pancreas cancer patients was very low. Eurocare-5 data showed that Western and Eastern European countries had a five-year age standardised relative survival for the period 2000-2007 in the vicinity of 5\% (Figure 5A). A higher survival was reported for Croatia (10.9\%), however, Eurocare- 5 survival analysis cautions that this may be due to a series of data quality related issues, such as poor follow-up, or underreporting of bad prognosis pancreas cancers. SURVCAN data reported survival for five Asian countries, going from $4.1 \%$ in Singapore to $17.2 \%$ in Hong Kong. 

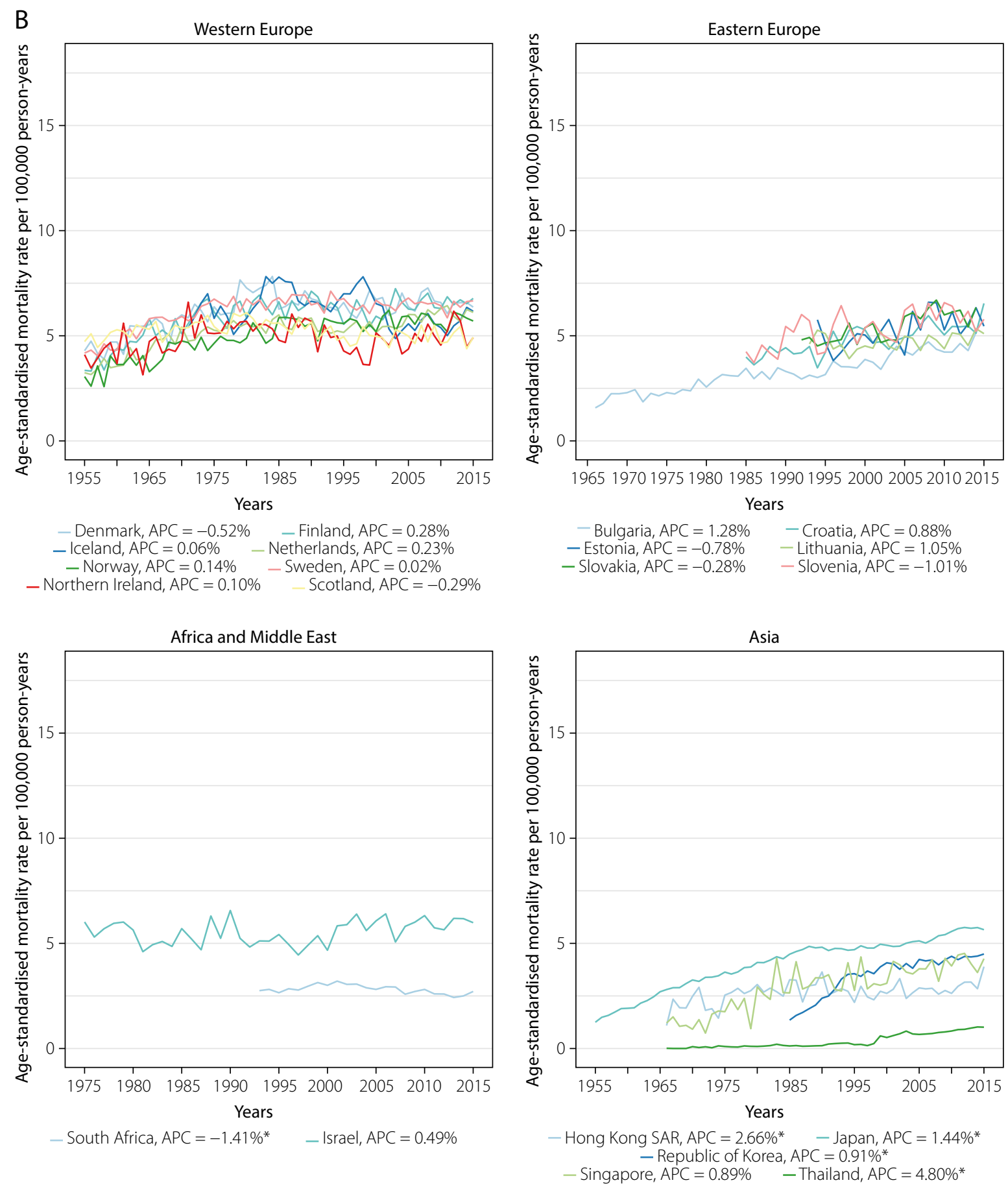

FIG. 3. Cont. (B), by region. APC - annual percentage change computed for the last ten years 2006-2015

Survival trends in the USA (Figure 5B) showed that five-year relative survival increased from $3.44 \%$ for men (5.38\% for women) in 1973 to $8.08 \%$ for men (10.22\% for women) in 2010. One-year relative survival was also low: $34.51 \%$ for men and $38.12 \%$ for women in 2014 . Survival rates were marginally better for women than for men.

Survival trends for Nordic European countries were available for diagnoses between 1966 and 2015, by fiveyear periods. They showed a situation similar to the USA, with one-year survival reaching $30 \%$ in recent years and five-year survival being below 10\% (Figure 5C).

Survival data by stage at diagnosis was available from the SEER database for the USA (Figure 5D). Fiveyear age-standardised relative survival showed almost no improvement in survival of distant stages over time, and little improvement for regional stages. Five-year survival for localised stages has increased to almost $36 \%$ in 2010 . 

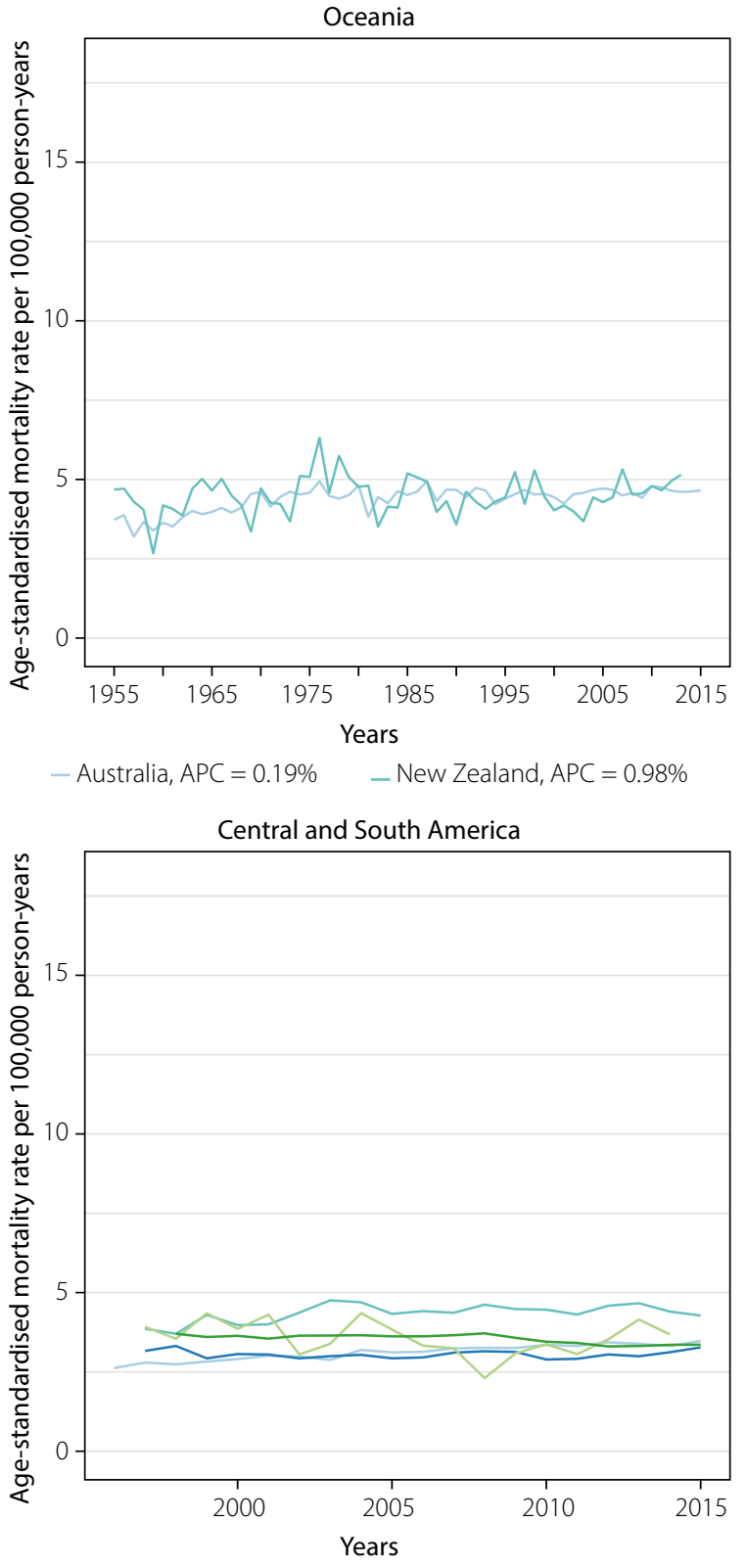
$\begin{aligned} \text { - Brazil, } \mathrm{APC} & =0.88 \% * \quad-\text { Chile, } \mathrm{APC}=-0.09 \% \\ - \text { Colombia, APC } & =0.38 \% \quad-\text { Costa } \mathrm{Rica}, \mathrm{APC}=3.36 \% \\ - \text { Mexico, } \mathrm{APC} & =-1.27 \% \%^{*}\end{aligned}$

Survival was highest for the younger age groups and was increasingly lower for older age groups (data not shown).

\section{DISCUSSION}

Disparities in pancreas cancer incidence and mortality were observed around the world. Higher incidence rates for both genders were observed in Europe, North America, Oceania and Eastern Asia compared to countries from Southern Asia, Central and South America and Africa. Higher mortality rates were observed in Europe, the Middle-East, Oceania and North America while lower rates were observed in Asia, Central and South America and Africa with the exception of Japan and the Republic of Korea which have relatively high

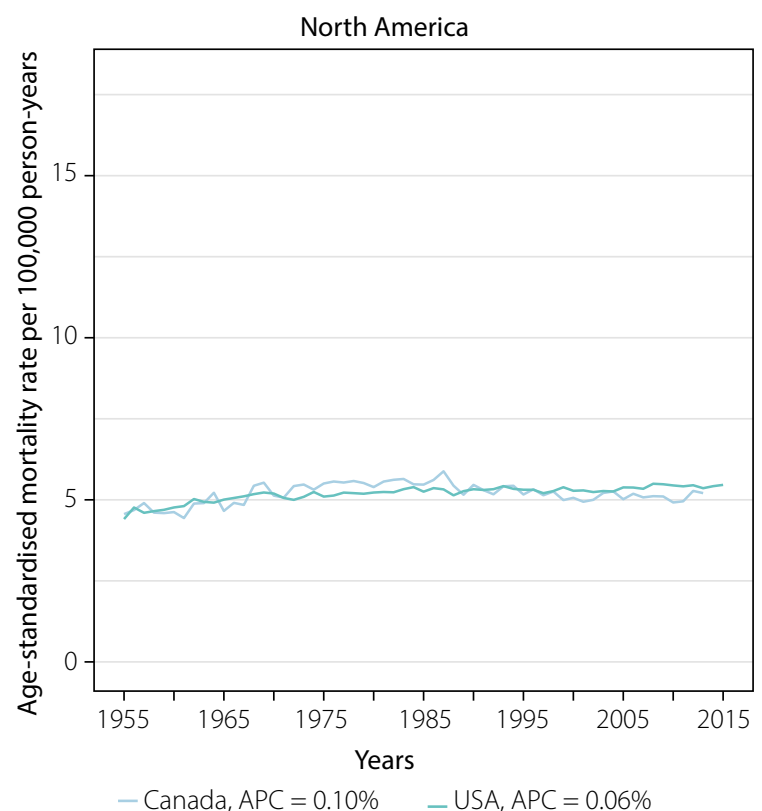

FIG. 3. Cont. (B), by region. APC - annual percentage change computed for the last ten years 2006-2015

mortality rates in both genders, in recent years. Although incidence and mortality rates are lower in Asian countries, important increases in rates were observed in the last decades for both genders. These increasing trend were also observed in China [17] and Taiwan [18]. In addition to these geographical disparities, a gender difference was observed for both incidence and mortality, with slightly higher rates in men than in women and more favourable recent trends for men than for women. In all studied countries, incidence of pancreas cancer was close to the mortality which was translated into very low survival rates observed worldwide (3.0-17.2\%) with the chances of survival declining drastically between the first and the fifth year after diagnosis. Better survival was 


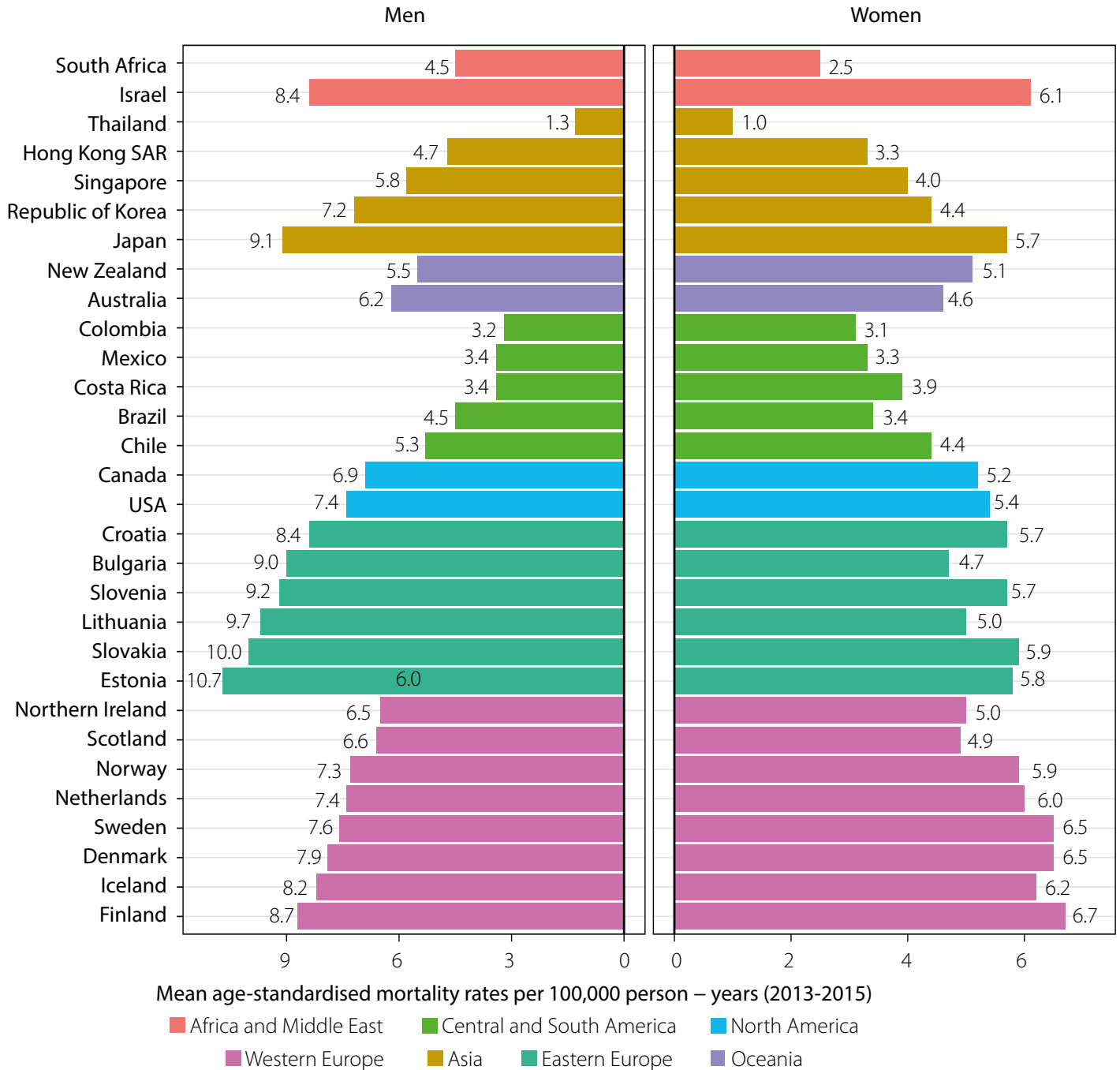

FIG. 4. Mean age-standardised pancreas cancer mortality over the period 2013-2015, by country and by gender

observed for tumours diagnosed at earlier stages, but even patients diagnosed with localised tumours had low five-year survival (35\%).

Geographical disparities in incidence may arise from different diagnostic capacity across countries. Indeed, higher incidence in developed countries could reflect a larger capacity of diagnostic compared to that of less developed countries, rather than the aetiology of pancreas cancer itself [19]. Also, more accurate diagnoses could be made in developed countries because of their more advanced health care systems. In Japan, the introduction of non-invasive imaging techniques such as ultrasound and computed tomography in 1981 has certainly improved the detection rate of pancreas cancer and its diagnostic accuracy [20]. The improvement in diagnostic methods and death certification of pancreas cancer may also explain the differences in mortality trends around the world. The important increases in pancreas mortality observed in Asian countries could also be explained by the progressive adoption of a western lifestyle.
Smoking is the best established risk factor leading to pancreas cancer, explaining about $25 \%$ of all cases $[21,22]$. Hence, another potential hypothesis for these differences could come from the differences in smoking patterns across countries. As many middle-income countries are still in the early stage of the tobacco epidemic [23], the effects of the exposure to smoking carcinogens will later be observed in these populations. Tobacco smoking may also explain the different trends in mortality observed worldwide. Some trends in pancreas cancer mortality reflect patterns of tobacco consumption. For example, declines in pancreas cancer mortality occurring in the eighties in North America, Oceania or Western Europe correlate well with the implementation of tobacco control. Other important risk factors such as diabetes and obesity [22] may have had an impact on the recent pancreas cancer incidence and mortality trends, given that obesity and diabetes have been rising during the last decades. These factors would explain the levelling off observed in North America, Oceania and Western Europe. 
A Finland

Denmark

Sweden

Netherlands

Norway

Scotland

Northern Ireland

Canada

Estonia

Slovakia

Lithuania

Slovenia

Bulgaria

Croatia

India

Republic of Korea

Singapore

Hong Kong SAR

Thailand

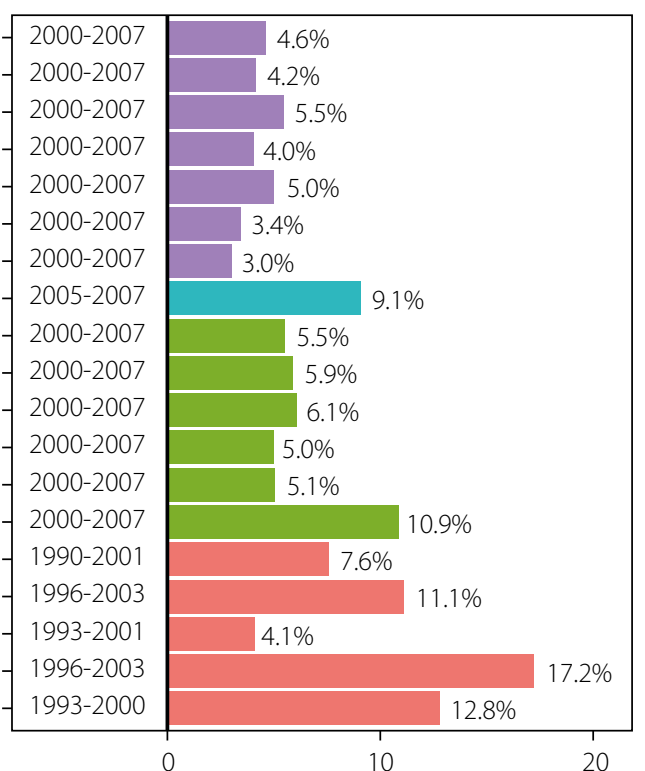

Age standardised 5-years relative survival (\%)

Asia Eastern Europe

North America Western Europe

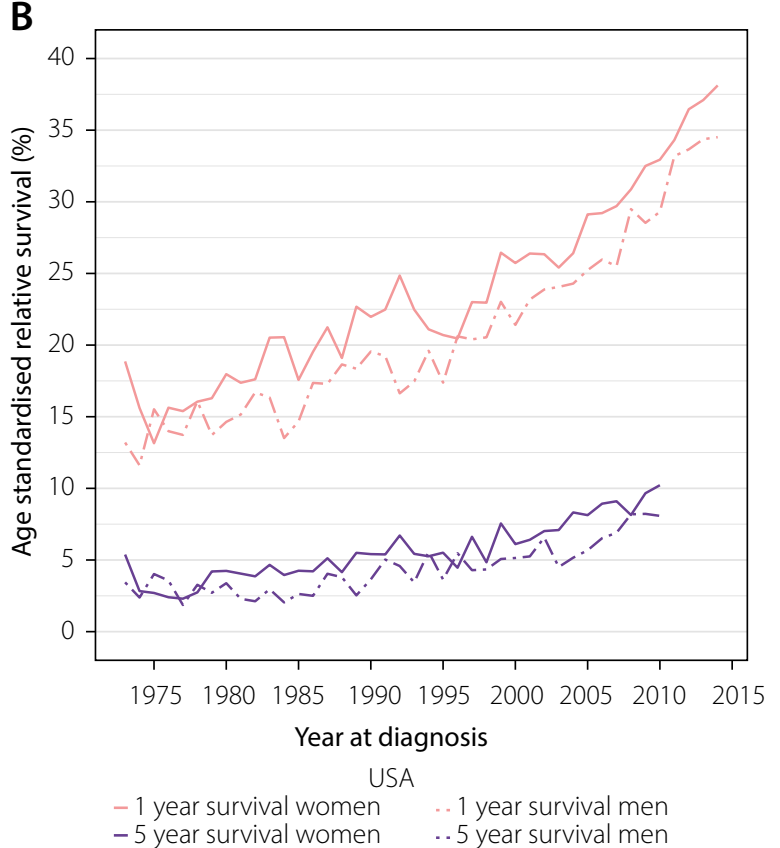

- 5 year survival women $\quad .5$ year survival men
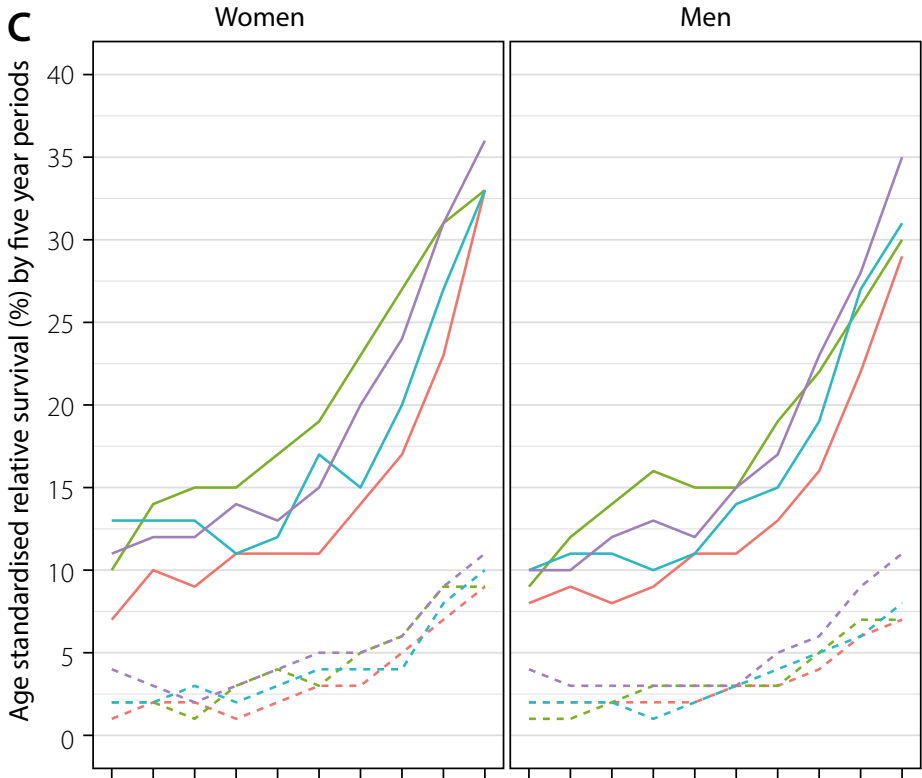

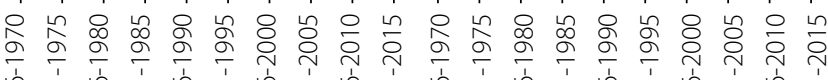

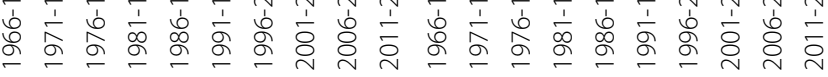

D

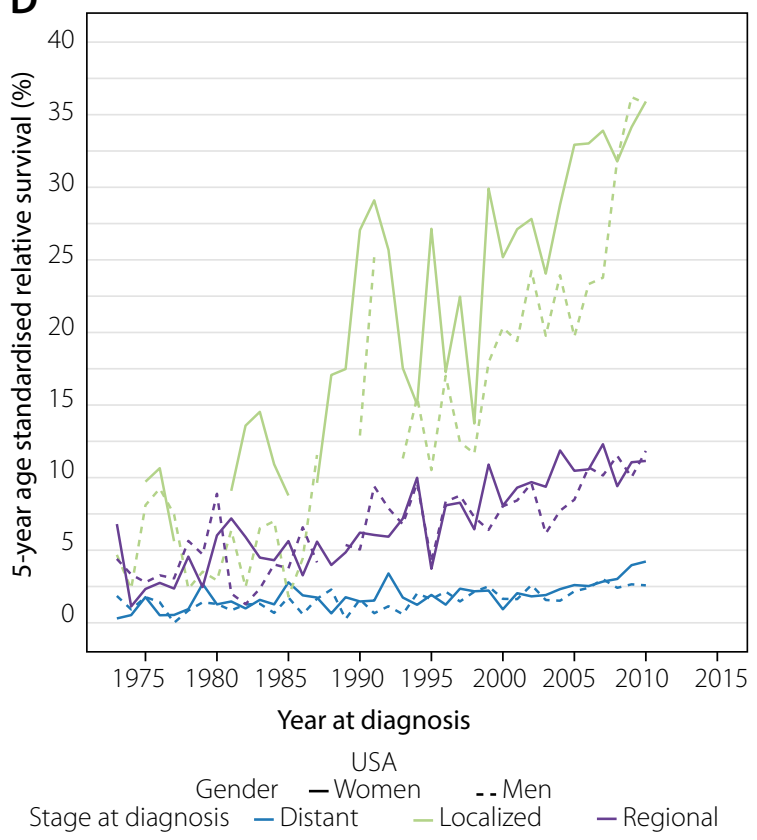

Period of diagnosis

- 1-year survival $\quad-. \cdot 5$-year survival

Country —Denmark — Finland — Norway — Sweden

FIG. 5. Pancreatic cancer age-standardised relative survival. A) Five-year age-standardised relative survival by country for both genders combined. B) One- and five-year age-standardised relative survival by year at diagnosis and by gender in the USA.C) One- and five-year age-standardised relative survival by country, by gender, and by period of diagnosis in the Nordic European countries. D) Five-year age-standardised relative survival by stage at diagnosis, by gender, and by year at diagnosis in the USA 
Concerning the gender differences, it is not quite clear why rates are slightly higher in men compared to women but a potential explanation would be that they are less exposed than men to environmental risk factors for pancreas cancer, in particular smoking [24, 25]. Another hypothesis would be that female hormones could protect against pancreas cancer since oestrogen-only therapy appeared to reduce the risk of pancreas cancer in women [26]. This study tried to give a global picture of the burden of pancreas cancer worldwide through its incidence, mortality and survival. However, some limitations should be addressed. Firstly, due to the constraint of national registries, the incidence of pancreas cancer was depicted for only 26 countries including ten countries with regional registries. Some regional cancer registries were finally included to have a better worldwide representativeness. Nonetheless, these regional data could be less accurate since they do not cover the whole population and small populations are more prone to random fluctuations. Also, there are disparities in methods of registering and quality, coverage and completeness of cancer registration across countries [27]. Secondly, in order to compare incidence with mortality, an effort was made to take the same countries which lead to include countries with low quality of data for mortality in Thailand and South Africa [8]. Thirdly, comparison of incidence and mortality within and between countries is complex since periods of available data are different. Indeed, incidence data were available until 2012 while data on mortality were available until 2015 and periods of available data varied from country to country. Fourthly, the comparison of survival data between countries were limited. First because Eurocare and SEER data used the ICSS for age-standardisation while NORDCAN and SURVCAN data used an alternative approach. Second, because period of available data were different between countries. Fifthly, data in Africa are scarce, only Uganda for incidence and South Africa for mortality were available which prevent to conclude on the burden of pancreas cancer in Africa. However, the low occurrence of pancreas cancer observed in Uganda was also confirmed in Middle Africa with incidence rate of 1.0 [28]. The epidemiology of pancreas cancer in low and middle income countries is poorly understood, with a dearth of available data, and need to be improved.

\section{CONCLUSIONS}

This article provides an overview of the current situation of pancreas cancer worldwide. Disparities in pancreas cancer incidence and mortality were observed around the world with generally higher rates in high income countries compared to low and middle income countries. Slightly higher rates were observed in men compared to women for both incidence and mortality. Globally, pancreas cancer mortality rates were close to incidence rates which reflects the poor prognosis of this cancer with five-year survival rates below $10 \%$. However, increases in survival rates since the 1970's and better survival in patients with a localised cancer give some hope for the future and suggest that early detection through the screening of population at risk and the development of molecular biomarkers should be the priority to improve outcomes of pancreas cancer.

\section{References}

1. Viudez A, De Jesus-Acosta A, Carvalho FL, et al. Pancreatic neuroendocrine tumors: Challenges in an underestimated disease. Crit Rev Oncol Hematol 2016; 101: 193-206.

2. Helmink BA, Snyder RA, Idrees K, et al. Advances in the surgical management of resectable and borderline resectable pancreas cancer. Surg Oncol Clin N Am 2016; 25: 287-310.

3. Bray F, Znaor A, Cueva P, et al. Planning and developing population-based cancer registration in low-and middle-incomesettings. IARC Technical publication No 43. World Health Organisation, France 2015

4. Bouvier AM, Bossard N, Colonna M, et al. Trends in net survival from pancreatic cancer in six european latin countries: Results from the sudcan population-based study. Eur J Cancer Prev 2017; 26 Trends in cancer net survival in six European Latin Countries: the SUDCAN study: S63-S69.

5. De Angelis R, Sant M, Coleman MP, et al. Cancer survival in Europe 1999-2007 by country and age: Results of eurocare-5 a population-based study. Lancet Oncol 2014; 15: 23-34.

6. Quante AS, Ming C, Rottmann M, et al. Projections of cancer inidence and cancer-related death in Germany by 2020 and 2030. Cancer Med 2016; 5: 2649-2656.

7. Rahib L, Smith BD, Aizenberg R, et al. Projecting cancer incidence and deaths to 2030: The unexpected burden of thyroid, liver, and pancreas cancers in the united states. Cancer Res 2014; 74: 2913-2921.

8. Mathers CD, Fat DM, Inoue M, et al. Counting the dead and what they died from: An assessment of the global status of cause of death data. Bull World Health Organ 2005; 83: 171-177.

9. Ferlay J, Colombet M, Bray F. Cancer incidence in five continents. Ci5plus. IARC Cancerbase 2018; 9. Available from: http://ci5.iarc.fr (accessed: 10 June 2019).

10. Engholm G, Ferlay J, Christensen N, et al. Nordcan: Cancer incidence, mortality, prevalence and survival in the Nordic countries. Association of the Nordic cancer registries. 2018. Available from: http://www.ancr.nu (accessed: 10 June 2019).

11. WHOMortality Database. Available from: https://www.who.int/ healthinfo/mortality_data/en/ (accessed: 10 June 2019).

12. United Nations. World population prospects. The 2015 revision. New York 2015, USA: United Nations.

13. Lepage C, Capocaccia R, Hackl M, et al. Survival in patients with primary liver cancer, gallbladder and extrahepatic biliary tract cancer and pancreatic cancer in Europe 1999-2007: Results of eurocare-5. Eur J Cancer 2015; 51: 2169-2178.

14. Sankaranarayanan R. Cancer survival in Africa, Asia, the Caribbean and central America. IARC Sci Publ 2011; 162: 1-5. 
15. Hurton S, MacDonald F, Porter G, et al. The current state of pancreatic cancer in Canada: incidence, mortality, and surgical therapy. Pancreas 2014; 43: 879-885.

16. Corazziari I, Quinn M, Capocaccia R. Standard cancer patient population for age standardising survival ratios. Eur J Cancer 2004; 40: 2307-2316.

17. Jia X, Du P, Wu K, et al. Pancreatic cancer mortality in China: characteristics and prediction. Pancreas 2018; 47: 233-237.

18. Tseng CM, Huang SP, Liao WC, et al. Incidence and mortality of pancreatic cancer on a rapid rise in Taiwan, 1999-2012. Cancer Epidemiol 2017; 49: 75-84.

19. Ferlay J, Steliarova-Foucher E, Lortet-Tieulent J, et al. Cancer incidence and mortality patterns in Europe: Estimates for 40 countries in 2012. Eur J Cancer 2013; 49: 1374-1403.

20. Lin, Tamakoshi A, Wakai K, et al. Descriptive epidemiology of pancreatic cancer in Japan. J Epidemiol 1998; 8: 52-59.

21. Lowenfels AB, Maisonneuve P. Epidemiology and risk factors for pancreatic cancer. Best Pract Res Clin Gastroenterol 2006; 20: 197-209.

22. Maisannevue Lowenfels AB Risk factors for pancreatic cancer: a summary review of meta-analytical studies. Int J Epidemiol 2015; 44: 186-198.

23. Gajalakshmi CK, Jha P, Ranson K, Nguyen S. Global patterns of smoking and smoking-attributable mortality. In P. Jha, F. Chaloupka (Eds.), Tobacco use and its consequences. World Bank 2000. Available from: https://pdfs.semanticscholar.org/19d5/5ee3493255c1c0e5dc90ff21e3fdaa276d80.pdf (accessed: 10 June 2019).

24. Parkin DM, Boyd L, Walker LC. The fraction of cancer attributable to lifestyle and environmental factors in the UK in 2010. Br J Cancer 2011; 105 Suppl 2: S77-81.

25. Parkin DM, Bray F, Ferlay J, Pisami P. Global cancer statistics, 2002. CA Cancer J Clin 2002; 55: 74-108.

26. Lee E, Horn-Ross PL, Rull RP, et al. Reproductive factors, exogenous hormones, and pancreatic cancer risk in the CTS. Am J Epidemiol 2013; 178: 1403-1413.

27. Bray F, Znaor A, Cueva P, et al. Planning and developing population-based cancer registration in low-and middle-income. Available from: http://www.rho.org/files/IARC_Planning_developing_cancer_registries_2014.pdf (accessed: 10 June 2019).

28. Ferlay J, Soerjomataram I, Ervik M, et al. Globocan 2012 v1.0, cancer incidence and mortality worldwide: Iarc cancerbase no.m11. International Agency for Research on Cancer, Lyon, France 2013. Available from: https://publications.iarc. fr/Databases/Iarc-Cancerbases/GLOBOCAN-2012-Estimated-Cancer-Incidence-Mortality-And-Prevalence-Worldwide-In-2012-V1.0-2012 (accessed: 10 June 2019). 
APPENDIX S1. List of regional registries included (in alphabetical order)

\begin{tabular}{|l|c|c|}
\hline Country & Registries & Period available \\
\hline Australia & $\begin{array}{c}\text { Queensland, South Australia, Tasmania, Victoria, Western Australia, Nor- } \\
\text { thern territories }\end{array}$ & $1993-2012$ \\
\hline Brazil & Goiania & $1993-2012$ \\
\hline Canada & All except Nunavut, Quebec, and Yukon & $1983-2012$ \\
\hline Colombia & Cali & $1983-2012$ \\
\hline India & Chennai & $1983-2012$ \\
\hline Japan & Musan, Seoul, Ulsan, Gwangju, Incheon & $1998-2010$ \\
\hline Korea & Chiang Mai, Knon Kaen, Songkhla, Lampang & $1999-2012$ \\
\hline Thailand & Kampala & $1993-2012$ \\
\hline Uganda & California: San Francisco; Connecticut; Georgia: Atlanta; Hawaii; lowa; Mi- \\
USA & chigan: Detroit; New Mexico; Utah; Washington: Seattle (SEER registries) & $1993-2012$ \\
\hline
\end{tabular}

\section{APPENDIX S2. Literature search for survival data}

The literature search in the PubMed database was performed in November 2018, for publications reporting national or regional pancreas cancer survival rates. Eligible studies needed to be population-based and to report age-standardised five-year relative survival. Only reports for the countries included in this study (as described in the Methods section) were included. Studies on specific sub-groups of populations (such as specific treatment) were excluded.

The search strategy yielded 464 results, 406 of which were excluded based on title and abstract. Of the remaining 58 publications, only one fit the eligibility criteria and was included in this study. The following Pubmed search query was used:

(survival[Title/Abstract])

\section{AND}

("pancreas cancer" [Title/Abstract] OR "pancreas neoplasm" [Title/Abstract] OR "pancreas carcinoma" [Title/ Abstract] OR "pancreatic cancer" [Title/Abstract] OR "pancreatic neoplasm" [Title/Abstract] OR "pancreatic carcinoma" [Title/Abstract])

AND

(Europe [Mesh] OR "north america" [Mesh] OR "south america" [Mesh] OR "central america" [Mesh] OR "asia" [Mesh] OR Africa [Mesh] OR "oceania” [Mesh] OR countr* [Title/Abstract] OR nation* [Title/Abstract] OR world [Title/Abstract] OR global [Title/Abstract])

AND

(“rate”" [Title/Abstract] OR "trend"” [Title/Abstract]) 